\section{A new Approach to increasing Diversity in Engineering at the Example of Women in Engineering}

Andrea I. Schäfer

Environmental Engineering, University of Wollongong, NSW 2522, Australia Schaefer@uow.edu.au, ph +61 242213385 , fax +61 242214738

[submitted to European Journal of Engineering Education Nov 2005]
Abstract: A new initiative to incorporate diversity issues into the common engineering curriculum at the University of Wollongong (UoW) in Australia is outlined and the effect on student awareness quantified. The diversity issues were illustrated at the example of women in engineering seeing that the numbers of women in engineering have dropped drastically over the last five years at UoW. However, the methodology applied can be adjusted to any diversity group to suit needs of the institution performing the activity. The method is based on the hypothesis that raising awareness and understanding across the entire student body will be a first step to change. The approach is different to the traditional recruitment and marketing approach of convincing women to try engineering with little follow up support. The initiative involves a diversity lecture delivered to all fourth year engineering students as part of a compulsory management subject. It is anticipated that with the current approach al students are made aware of the problems women expect to face in the engineering profession. This awareness is hoped to bring about some of the required change in culture and prepare women to draw on available support. The strategy does not exclude men, but includes men as instruments for positive on avilable change through an understanding of the benefirs of a gender balanced and diverse work environment on everyone. The initiative is popular with students who through their feedback are requesting more such
activities, in particular in early years of engineering education. Keywords: diversity lecture, women in engineering, gender balance, positive change, culture.

\section{Diversity in Engineering - Gender issues}

Diversity is an important issue in globalisation and competitiveness of institutions and corporate entities $[1,2]$. A number of professions are traditionally not diverse and are in consequence further repelling minorities to consider such professions as career choices. This results in specific cultures quite different to what is seen as a diverse culture where "everyone feels included, appreciated and valued" and "everyone can achieve their potential" [3]. In consequence some professions like engineering may miss out on valuable contributions and new thinking approaches which a diverse workforce may add and which may indeed be needed to achieve the exceptional performance required to solve today's complex engineering problems. Lewis et al. [3] have addressed this issue comprehensively in their diversity guide for the engineering profession.

Diversity has a number of dimensions ranging from personality to organisational contexts, with gender, race and ethnicity, physical ability and age probably being the most predominant differences, and, applied to engineering, the conflict between internal and projected dimensions may explain some of the marginalisation effects observed [4]. To tackle the diversity challenge one difference has been selected in this study - which is thor, personal interest and hence the area of greatest likelihood of being able to contribute to a solution. The methodology, however, is directly applicable to other diversity issues.

Diversity of the student body at academic institutions has immediate economic benefits. In an age where many academic institutions compete for enrolments, in particularly in engineering, not drawing on the pool of women, for example, reduces revenue. This has motivated many institutions to maintain level of recruitment and marketing activities ranging from open days, school visits, sometimes with special emphasis on women, to maintaining some form of women in engineering activity. "A department's willingness to accept responsibility for maintaining a student-initiated program is an obvious indicator of its stance toward women" [5]. Maintenance of voluntary driven programs, by either students or token female academics has, however, limited prospects of success. Often neither formal recognition for such engagements, nor a serious commitment (in terms of patronage, work load 
acknowledgement or substantial financial support) from management are provided. Individual women are often motivated by their own needs to contribute to such programs. Such programs can provide a "safe" environment for both students and faculty [6]. It should be noted here that many women enter the field through encouragement by core males which is an influence not to be neglected in recruitmen [7]. According to Jawitz and Case [8], "instead of the traditional activities which try to persuade women that they should try engineering and then fit into the culture $[\ldots]$ we need to create a new engineering culture". Green [9] outlines the important shift in the engineering tradition which require new skillsets and ultimately a different student body. As a start, real change can only be achieved a organisational and government level, including enforcement of anti-discrimination laws as well as more proactive approaches of employment equity and diversity units. Despite many efforts with regards to family-friendly policies, women often experience "marginal positions in organisation power hierarchies" [2].

The New South Wales Sex Discrimination Commissioner takes an interesting stance on recruitment activities saying that to attract women students and staff to traditionally male professions, institutions activities Saying that to need to show that minities are successful through promion and of the problom fiom based on merit [11] and Robst et al. the effect of promotion on the perception of fair treatment in institutions [12]. In educational programs at student level much depends on learning style an curriculum content where practices that enhance self-esteem and confidence are seen as valuable [13]. This addresses the problem of the often low retention of women in educational programs, engineering academia as well as the engineering profession. In fact, while in Australia $15 \%$ of the undergraduate engineering enrolments are women, in the workforce this reduces to 5\% [14]. Low retention has been attributed to "the unfriendly, even hostile culture of engineering" and the discrepancy between the need of women to "work cooperatively, and with a holistic perspective" as opposed to the more established hierarchical arrangements. In academia the "difficulty in collaborating with colleagues" leads to job offer rejections, marginalistion of women in enginering positions and retention generally tends to be very low [1] Accoling to recuimt expers "unu be very low [1]. A2. The nate to exit trends" [2]. The nature of such cultures tend to be "reactive, hierarchical and lacking in people skills" $[15]$. The characteristics of cultures that are more attractive to women encompass formal support and encouragement from leaders, critical mass of women, access to networks, flexibility and family friendly policies, and commitment to values [16]. Performance also increases in pleasant environments, where staff and students are trusted and appreciated, and can have fun [17] and possibly also where friendships between advisors and students exist [18].

As presented by Ayre [15], women need to love their work and be 'crusaders', meaning they need to have dedication, courage and drive. If those traits are combined with female qualities of intuitiveness, flexibility and people skills this obviously brings great value to the profession. It is well established that women often outperform men in engineering academically [3] and have to be better to succeed professionally [2]. However, over-functioning is seen as a 'survival' not a 'thriving' strategy. The credit for this performance goes rarely to the intellect or the work ethic of women, but to specia perial reatter instilled by the prence an pen in fact been tepored to be fearul of ent an may in fact become a career limiting factor for women when translated into exclusion from the engineering community, boys-clubs, putting assertive women in their place, withholding of information or bullying tactics. Many forms of discrimination are in fact (and often due to anti-discrimination laws and policies) becoming subtle and difficult to uncover.
It can further be very difficult for women to get hold of mentors understanding the complexity of issues and committed to provide upward mobility for their protégés [2]. Mentoring is a very relational activity and committed to provide upward mobility for their protégés [2]. Mentoring is a very relational activity
and the expectations men and women have of mentoring activities is substantially different [18]. and the expectations men and women have of mentoring activities is substantially different [18].
Women are generally expecting to develop a relationship of mutual trust and understanding, while men are more focused on directive advice. On the educational front, new approaches in teaching may be needed to reach women. Shull and Weiner [19], for example, describe an institutional practice that leads to increased retention of women. Motivation, effort and persistence are targeted in this educational approach.

The image of engineering is masculine - indeed, engineering has a huge image problem [20]. The perception of engineering as masculine is, according to Phipps [21] a reason for the female minority. Hence the male over-representation and perception both cause and are caused by the underrepresentation of women. To achieve change, it is not new advantages or special measures that need to be created for women, in fact many of those create further resentment in men. It is men that really need to be cond boy are unlikely to change, simply because they are told that they have to. They will need to be convinced that there are reasons". It is in this spirit the "diversity lecture" described in this paper was developed. It was our hypothesis that raising awareness and understanding will reduce the fear expressed by so many men and may instil a culture of support and collaboration. Understanding of the positive consequences of more women in engineering (such as more fun, higher family incomes, and better family-life balance for all including better paternity leave arrangements) for men would further enhance progress. In fact, Stonyer [22] expresses that a new partnership between men and women in engineering can stimulate the communication required to achieve a realistic consensus about scientific rationality may be the key to more women enjoying the success and participating in engineering more fully. The initiative will lead to an increased diversity sensitivity within technical education which, according to Hermanussen and Booy, is an important factor in achieving change [23]

\section{Design of the diversity lecture}

At UoW, a regional university, the female participation in engineering was $10-12 \%$ in the 1997 to 2002 period while the national average was $15.6 \%$ in 2002 . The values of female student percentages by discipline at UoW are presented in Table 1 Speaker selection and content of presentations of the "diversity lecture"

\begin{tabular}{|c|c|c|}
\hline Presenter & Duration (mins) & Topic \& Suggested Content \\
\hline Pro Vice Chancellor (Research) & 5 & Opening \& introduction of EEO activities at UoW \\
\hline Lecturer & 10 & $\begin{array}{l}\text { Welcome \& objectives of lecture } \\
\text { - } \text { why focus on women's issues } \\
\text { - cultural diversity } \\
\text { - } \text { readings } \\
\text { - } \text { assessment task }\end{array}$ \\
\hline $\begin{array}{l}\text { Director Equal Employment } \\
\text { Opportunities (EEO) }\end{array}$ & 10 & $\begin{array}{l}\text { Statistics of women in } \\
-\quad \text { undergraduate \& postgraduate degrees } \\
\text { - } \text { academia }\end{array}$ \\
\hline
\end{tabular}


Schäfer, A.I. (2006) A new Approach to increasing diversity in engineering at the example of women in engineering

European Journal of Engineering Education, Volume 31, Issue 6 December 2006 , pages 661 - 671

DOI: $10.1080 / 03043790600911738$

\begin{tabular}{|c|c|c|}
\hline & & - engineering workforce \\
\hline Director EEO & 10 & $\begin{array}{l}\text { Issues of discrimination overview } \\
\text { - bullying } \\
\text { - harassment } \\
\text { - family juggles etc. }\end{array}$ \\
\hline $\begin{array}{l}\text { Postgraduate Student } \\
\text { Representative }\end{array}$ & 10 & $\begin{array}{l}\text { Women Postgraduates in Engineering } \\
-\quad \text { the student perspective of diversity } \\
-\quad \text { the situation for postgraduates }\end{array}$ \\
\hline $\begin{array}{l}\text { Female Engineer from Local } \\
\text { Industry }\end{array}$ & 15 & $\begin{array}{l}\text { Women in Engineering } \\
\text { - differences in the way women operate } \\
\text { - contributions of women to the workforce }\end{array}$ \\
\hline $\begin{array}{l}\text { Female Engineer from Local } \\
\text { Industry and University Council } \\
\text { Member }\end{array}$ & 15 & $\begin{array}{l}\text { Work or Cost of low Retention } \\
\text { - working parent } \\
\text { - work community \& collaboration } \\
\text { - staff availability } \\
\text { - family income etc. }\end{array}$ \\
\hline $\begin{array}{l}\text { Male Engineer from Local } \\
\text { Industry and Husband of an } \\
\text { Engineer }\end{array}$ & 15 & $\begin{array}{l}\text { The Engineering Family or seeing from the Male } \\
\text { Perspective } \\
\text { - being married to a female engineer } \\
\text { - juggling family issues between two careers }\end{array}$ \\
\hline $\begin{array}{l}\text { Flexible Learning Services } \\
\text { CEDIR, Acting Manager }\end{array}$ & 5 & $\begin{array}{l}\text { Assessment/Assignment } \\
-\quad \text { presentation of the Diversity in Engineering project }\end{array}$ \\
\hline Lecturer & 5 & Conclusions \& Collection of Questionnaires \\
\hline
\end{tabular}

Table 2 Questions asked in the anonymous questionnaire collected at the end of the lecture.

\begin{tabular}{|l|l|}
\hline 1 & Gender \\
\hline 2 & Status (Student/Academic Staff/General Staff) \\
\hline 3 & Engineering Discipline \\
\hline 4 & $\begin{array}{l}\text { One a scale of 0 (low) to } 10 \text { (high) awareness of diversity in engineering issues before attending this } \\
\text { lecture. Any comments on the answer? (such as reasons for level of awareness?) }\end{array}$ \\
\hline 5 & $\begin{array}{l}\text { One a scale of 0 (low) to } 10 \text { (high) awareness of diversity in engineering issues after attending this } \\
\text { lecture. Any comments on the answer? (such as how this lecture made a difference or why it didn't?) }\end{array}$ \\
\hline 6 & How could we improve the communication of diversity issues in engineering? \\
\hline 7 & Any comments to share on the lecture or associated issues. \\
\hline
\end{tabular}



Figure 1. Values indicate a significant decrease of women participation in some areas (environmental
engineering in particular with a drop from 37.5 to $22 \%$ over the years 2000-2003) while others are engineering in particular with a drop from 37.5 to $22 \%$ over the years $2000-2003$ ) while others are
stable or show a small increase. Overall this paints not a positive picture with current trends indicating stable or show a small increase. Overall this paints not a positive picture with current trends indicating
a further decrease. The student run women in engineering program (WIEN) has been without substantial financial and academic support for several years and operates at a minimum of activities. Staff support for the program is at the lower end of the priority list which is felt by both staff and students.

\section{[FIGURE 1]}

The initiative of the "diversity lecture" was started by the author by writing a proposal to gain support for strengthening the WIEN activity by creating a website and mailing list through a faculty service agreement for the Centre for Educational Development and Interactive Resources (CEDIR). While the proposal was successful, a condition of the grant was that the project had to be linked to a subject. After some discussion with the very supportive Associate Dean at the time it was decided that a best fit with teaching would be in one of the engineering management subjects. The change in subject coordinator provided further encouragement and it was agreed that one lecture would be dedicated to this initiative. While it was recognised that diversity did encompass other issues than gender, a focus on the gender issue was agreeable.

When designing the approach a number of factors were elucidated as important. Those were (1) reaching all students as opposed to members of the diversity group only, (2) an academic benefit linked to performance and learning on the issues, (3) visible institutional support for the activity, (4) clear definition of objectives and goals. The planned activity was incorporated into a fourth year management subject. Project Management and
Human Factors in Engineering (ENGG 461) is a fourth year subject that is compulsory for all civil, Human Factors in Enginecing (ENGG 461) is a fourth year subject that is conpulsory for all civi environmental, mining, mechatronics, mechanical and materials engineering students at UoW. On average about 100-120 students are enrolled in this subject, in session 12004 when this lecture was offered for the first time 108 students were enrolled.

The diversity topic was assigned one week in this subject and consisted of a $2 \mathrm{~h}$ lecture, $2 \mathrm{~h}$ tutorial as well as a brief assignment that was awarded bonus marks of $5 \% .83$ out of 108 students submitted this assignment. The assignment was marked (voluntarily by the author as no support for marking the assignments was available) and also analysed in terms of success of the lecture and response of students to the material presented. Given the reflective nature of the assignment this provided significant insights into the roadblocks in accepting women into the engineering workforce and some of the threats perceived by fellow students. Results of this assessment are not presented in this paper. A reading was provided to the students as part of the lecture and for the reflective learning exercise in the reasignm we The reas the assignment. The reading was the paper by Roberts and Ayre "Did she jump or was she pushed? A study of women's retention in the engineering workforce" [14]

The diversity lecture was designed to have the following objectives;

- raise awareness of diversity issues at the example of gender diversity

- emphasise that female engineers have often different qualities and that those qualities bring a distinct benefit to the engineering profession (collaboration versus competition; broad \& holistic versus linear \& focused thinking approaches)
- benefits of working in a socially (gender) balanced workplace for all

- economic benefits of keeping women in the workforce (for companies, the family income as well as society in general)

- advantages of family friendly practice for men (e.g. father and mother being able to take parental leave and spend fun time with children, etc)

Speakers were selected from a variety of backgrounds and given individual briefing on the content of their presentations. A number of "hidden agenda" items were identified which were not communicated to the students but were seen as important objectives;

- awareness in our female graduates that they are not alone when being marginalised, isolated etc. and pointing them towards possible sources for support

- reduce the fear of male engineers/graduates that women 'steal' their jobs and get hired because they are women (with the resulting consequences)

- become more inclusive of women to reduce marginalisation

- remove the glass ceilings so more women can reach the upper levels of responsibility and subsequently attract more women to the profession through visible leadership.

A number of guest speakers were invited to speak at the diversity lecture. The selection of speakers included a Pro-Vice Chancellor to signal importance to the Faculty of Engineering and students, the Director of the Equal Employment Opportunities (EEO) Unit to summarise statistics as well as outlin issues of discrimination, harassment, bullying, etc, a postgraduate student representative (in this case the President of the Wollongong University postgraduate Association (WUPA)) and a range of engineers from various management levels and organisations including a male engineer (married to an engineer). A list of those speakers and their briefs is presented in Table 1.

Invited to the lecture were all other general and academic staff as well as postgraduates of the Faculty. Response to this invitation was very low, limited to 2-3 female academics and postdocs. It is interesting to note that neither those responsible for increasing the number of female students nor faculty management showed interest in the activity.

Following the lecture a questionnaire was collected to assess the change in awareness as well as general response of the respor 50 sthe sts, 1 acado the 19 mechical, 8 mech whe 10 civil, 5 envir males; 50 students, 1 academic; 19 mechanical, 8 mechatronic, 10 civil, 5 environmental, 2 materials 1
chemical, 2 mining, 2 double degree science/chemical and arts/materials engineering students. The chemical, 2 mining, 2 double degree
questions summarised in [TABLE 1]

[TABLE 2] 
were asked in the questionnaire to obtain feedback on the diversity lecture. For future activities more emphasis will be placed on inviting colleagues and managers personally to attend and provide feedback in response to a low attendance and feedback rate at the first lecture despite a general invitation.

[TABLE 1]

[TABLE 2]

\section{Contents and feedback of the diversity lecture}

The guest lecturers presented the following key points. Following the introduction and welcome of the Pro Vice Chancellor (Research) who outlined the changes she has initiated and seen in the Faculty of Science.

The lecturer explained the importance of the issue to her and gave a few examples of happy and unhappy experiences during her engineering education. An emphasis was placed on how much fun it is for everyone to study in a gender balanced group and how much marginalisation and discrimination are still experienced in engineering. Readings were handed out and the assessment task outlined.

The Director of EEO gave the statistics- 56\% of Australian students are female while this figure in engineering is $14.9 \%$, and only $4.9 \%$ of professional engineers are female. Issues of hostile culture, family-work balance, and discrimination were outlined with an emphasis on bullying.

The postgraduate representative described her experience of studying chemical engineering which started with gender equality, but female retention was so low that only $25 \%$ completed, with lecturers catering mainly for the male student needs. An overseas experience (in Sweden) showed a complete absence of this gender bias at the university and in the workforce. From a postgraduate perspective, it appeared that women were seen as being in the field due to their gender, not merit. Women did not want to be treated differently to men but simply have the same opportunities. While there are more female postgraduates now, the on-time completion is of disadvantage to women due to the family-work balance. The suggestion was to encourage cross-gender cooperation and as supervisors be aware of the different needs and abilities of women. Women are needed on all hierarchical levels.

The first local engineer emphasised that women operate differently, but can do a great job with "real" engineering tasks such as responding to major industrial accidents. Women are physically different, hink differently and can be workforce, approach things in a different way and people tent to they do to men. The issue of the "broken women" was outlined- where being different is often perceived at being wrong and the outcome often to be sent to various training courses to be "fixed". The challenge obviously is to recognise the differences and use them for the benefit of the institution.
The second local engineer, with managerial responsibilities, focused on the costs incurred by not recruiting and retaining women in the engineering workforce. Finding good engineers is a globa challenge- so why limit recruit only from half the population? Growing a good engineer in a company takes 5-10 years and a drop out leaves a significant hole. Engineering needs clearly all personality types as diversity fosters the ability to innovate. Engineering does not attract women as its culture does not value or recognise the differences women contribute and the limiting culture gets bad press in the community.

The third local engineer, a token male presenter in the diversity lecture, presented his family situation, being married to an engineer, juggling two careers and the difficulties in always coordinating children and the needs of two professionals. He described the engineering network, in which staff share knowledge, resources, social activities and get access to mentoring. The success of individuals and organisations was described as depending on the alignment of individual career goals an organisation objectives, flexible human resources policies, the work-life balance and the retention organisational objectives, flexible
the skill/knowledge base- people.

Feedback obtained following the lecture was enormous. Students would talk about the lecture in the corridor, share experiences and tell others about it. Besides the handful of students departing from the corridor, share experiences and tell others about it. Besides the handful of students departing from the
lecture in protest, participation was active and interest high. The questionnaire results reflected this lecture in protest, participation was active and interest high. The questionnaire results reflected this
impression. A significant increase in awareness was achieved and results from questionnaires are impression. A significant increase in
summarised in Figure 2 and Figure 3.

[FIGURE 2]

Some students were obviously confronted with diversity issues for the first time. This can be observed in Figure 2. The students of very low awareness of the issues experience significant increases. The distribution of awareness after the lecture was narrow and the increase of awareness achieved was 2-3 points. This is further illustrated in Figure 3.

[FIGURE 3]

Additional feedback obtained from the questionnaires were a number of very interesting suggestions. Students suggested that this lecture be not presented in their fourth and last year only but that it ought to be presented in addition in first year. This is an achievable suggestion as first year subjects that are attended by all engineering students are available and running such an activity then may better the undergraduate experience of students.

There was some degree of surprise at the value of employees and the costs involved in loosing trained staff. Students expressed concern about the situation that affects the female friends they have made 
during their education and commitment to change from the questionnaires was overwhelming. It appears that an immediate problem in the discrimination that women face in engineering educationa institutions is the lack of awareness of issues amongst their colleagues. Hence raising such awarenes with in-house programs, training and information distribution has the potential to alleviate a significan part of the problem. It is noteworthy that the token male presenter played an important role in the lecture in that he connected very well with the male students, which made the message relevant an accessible to the majority of students. This indicates that men have a very important role to play as advocates for change with regard to gender diversity.

\section{Conclusions}

Increasing diversity amongst engineering students, in particular gender diversity, is not only a question of marketing and school visits. Important is also to demonstrate to those prospective students, that once gradated from such a discipline that attractive jobs can be obtained and that women indeed succeed in their chosen careers. Further, the fear that some of the men experience and express when seeing women succeed in engineering needs to be transformed into seeing the benefits of diversity. This raises suce (a) about the his corporate and the academic environment. The latter is an ethical responsibility that tends to be neglected when women are presented with a gloomy picture at school visits.

This paper has outlined an approach that addresses both those needs. In a "diversity lecture" that is compulsory for all engineering students, the diversity problem is outlined by a number of representatives with core objectives being to raise awareness, presenting role models of engineers an outline the benefits of diversity to all involved. The activity achieved a significant increase in awareness and extremely positive feedback from the students. Many expressed surprise at the issues raised and some women were shaken to the point of regret to have chosen engineering. This first step to change will possibly help retention in the profession if women enter prepared and face less of a feeling of aloneness when problems are encountered. However, much research remains to be done on those topics to identify the consecutive steps to change with a clear identification of how to bring about the cultural shift required for women to become valued contributors with critical mass. Maybe the increasing short will help exent pressure to attract women into the profession- and keep them. Academic institutions may then feel the need to follow.

Pru Goward, the Australian Sex Discrimination Commissioner at the Human Rights and Equal Opportunity Commission has a straightforward answer to increasing the proportion of women staff and students in traditionally male disciplines "Promote them. Women succeeding in a profession attracts other women". It is our job to create an environment where women can and want to perform as well a ensure that promotions are merit not gender or network based.

\section{Acknowledgements}

A/Prof Bill Zealey is thanked for his inspirational support and empathy, much of it caused by seeing daughters battling. A/Prof Peter Gibson is acknowledged for being open to change and offering to integrate diversity issues into the management subject. Further extensive discussions, flexibility an provision of the course outline are much appreciated. Dr Christine Brown and her staff at CEDIR are thanked for inspiring discussions surrounding the initial Faculty Service Agreement and the planned website development as well as data analysis of the questionnaires. Thanks to the speakers at the
Diversity in Engineering Lecture, all of whom have generously donated their time for what "just has to be done" as one of the speakers put it- Prof Margaret Sheil, Robyn Weekes, Donna Capararo, Leanne Treadwell, Kerrie Christian, and Richard Ainsworth. Robyn Weekes is thanked for her continuing efforts as the Director of Equal Employment Opportunities (EEO) and for taking up the idea of developing a student version of EEO Online. Much remains to be done. Julie Romanowski and Greg Hampton are acknowledged for the provision of insightful data of minority participation. The engineering students are thanked for their cooperation, in particular seeing that the assessment has been voluntary. The comments received have made this lecture one of my most satisfying teaching experiences. Last but not least I would like to thank Prof Adrian Lee and Jan McLean at UNSW for their continuous support in the Graduate Certificate in University Learning and Teaching, long after my departure from UNSW as a staff member. Maybe one day the diversity in engineering dream will fly.

\section{References}

1. Boyce, M.C., P. Chisholm, E.F. Crawley, L.J. Gibson, K.K. Gleason, N.A. Lynch, J.B. Vander Sande, Report of the Committee on Women Faculty in the School of Engineering at MIT. 2002, Massachusetts Institute of Technology.

2. Palermo, J., Breaking the cultural mould: the key to women's career success. A Hudson initiative to help businesses compete and succeed in the future, 2004. 20:20 Series: p. 1-40.

3. Lewis, S., R. Harris, B. Cox, Engineering a better workplace - a diversity guide for the engineering profession, ed. Women in Engineering. 2000, Barton, ACT: Institution of Engineers, Australia. 110.

4. Waller, A.A. A dynamical systems model for investigating diversity. in 33rd Annual Frontiers in Education. 2003. Westminster, CO, USA: IEEE.

5. Etzkowitz, H., C. Kemelgor, B. Uzzi, Athena unbound - The advancement of women in science and technology. 2000, Cambridge: Cambridge University Press. 282.

6. Hartman, H., M. Hartman. Empowering female students: SWE vs. disciplinary organization participation. in 33rd Annual Frontiers in Education. 2003. Westminster, CO, USA: IEEE

7. Noordenbos, G., Women in academies of sciences: from exclusion to exception. Women's Studies International Forum, 2002. 25(1): p. 127-137.

8. Jawitz, J., J. Case, Guest Editorial- Women in Engineering: Beyond the stats. International Journal of Engineering Education, 2002. 18(4): p. 390-391.

9. Green, M., Educating the new engineer. Transactions of Multi-Disciplinary Engineering, 2001. GE 25: p. 39-50.

10. Goward, P., Work/Family Issues in the New Federal Government's Agenda, Economic and Social Policy Public Lecture. 2004: Wollongong, NSW, Australia.

11. Hersh, M., The changing position of women in engineering worldwide. IEEE Transactions of Engineering Management, 2000. 47(3): p. 345-359. 
Schäfer, A.I. (2006) A new Approach to increasing diversity in engineering at the example of women in engineering,

European Journal of Engineering Education, Volume 31, Issue 6 December 2006 , pages 661 - 671

DOI: $10.1080 / 03043790600911738$

12. Robst, J., J. VanGilder, S. Polacheck, Perceptions of female faculty treatment in higher education: which institutions treat women more fairly? Economics of Education Review, 2003. 22: p. 59-67.

13. Williams, A., P. Turrell, R. Wall, Let's TWIST: Creating a conductive learning environment for women. International Journal of Engineering Education, 2002. 18(4): p. 447-451.

14. Roberts, P., M. Ayre, Did she jump or was she pushed? A study of women's retention in the engineering workforce. International Journal of Engineering Education, 2002. 18(4): p. 415-421.

15. Ayre, M., The CREW Report: Careers review of engineering women. Women engineers: The continuing crusade. A review of current literature. Transactions of Multi-Disciplinary Engineering, 2001. GE 25: p. 1-34.

16. Chesterman, C., A. Ross-Smith, M. Peters, Senior women execultives and the cultures of management. Australian Technology Network Women's Executive Development Program, 2004. www.uts.edu.au/oth/wexdev/pdfs/cultures_of_mgt.pdf (accessed 07/2005): p. 1-34.

17. Shepherd, E., Achieving results through leadership and cultural change. Transactions of MultiDisciplinary Engineering, 2001. GE 25: p. 35-38.

18. Vesilind, P.A., Mentoring Engineering Students: Turning Pebbles into Diamonds. Journal of Engineering Education, 2001. July: p. 407-411.

19. Shull, P.J., M. Weiner, Thinking inside the box: self-efficacy of women in engineering. International Journal of Engineering Education, 2002. 18(4): p. 438-446.

20. Tietjen, J.S., Why so few women, still? IEEE Spectrum, 2004. 41(10): p. 57-58.

21. Phipps, A., Engineering women: The 'Gendering' of professional identities. International Journal of Engineering Education, 2002. 18(4): p. 409-414.

22. Stonyer, H., Making Engineering Students - Making Women: The Discursive Context of Engineering Education. International Journal of Engineering Education, 2002. 18(4): p. 392-399.

23. Hermanussen, R., C. Booy, Equal opportunity in higher technical education: past, present and future. International Journal of Engineering Education, 2002. 18(4): p. 452-457.
Table 1 Speaker selection and content of presentations of the "diversity lecture"

\begin{tabular}{|c|c|c|}
\hline Presenter & Duration (mins) & Topic \& Suggested Content \\
\hline Pro Vice Chancellor (Research) & 5 & Opening \& introduction of EEO activities at $\mathrm{UoW}$ \\
\hline Lecturer & 10 & $\begin{array}{l}\text { Welcome \& objectives of lecture } \\
\text { - } \text { why focus on women's issues } \\
\text { - cultural diversity } \\
\text { - } \text { readings } \\
\text { - } \text { assessment task }\end{array}$ \\
\hline $\begin{array}{l}\text { Director Equal Employment } \\
\text { Opportunities (EEO) }\end{array}$ & 10 & 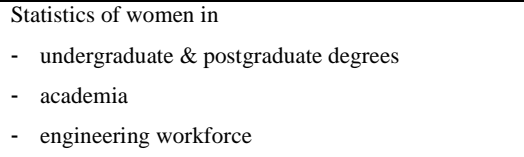 \\
\hline Director EEO & 10 & $\begin{array}{l}\text { Issues of discrimination overview } \\
\text { - bullying } \\
\text { - harassment } \\
\text { - family juggles etc. }\end{array}$ \\
\hline $\begin{array}{l}\text { Postgraduate Student } \\
\text { Representative }\end{array}$ & 10 & $\begin{array}{l}\text { Women Postgraduates in Engineering } \\
-\quad \text { the student perspective of diversity } \\
\text { - the situation for postgraduates }\end{array}$ \\
\hline $\begin{array}{l}\text { Female Engineer from Local } \\
\text { Industry }\end{array}$ & 15 & $\begin{array}{l}\text { Women in Engineering } \\
\text { - differences in the way women operate } \\
\text { - contributions of women to the workforce }\end{array}$ \\
\hline $\begin{array}{l}\text { Female Engineer from Local } \\
\text { Industry and University Council } \\
\text { Member }\end{array}$ & 15 & $\begin{array}{l}\text { Work or Cost of low Retention } \\
\text { - working parent } \\
\text { - work community \& collaboration } \\
\text { - staff availability } \\
\text { - family income etc. }\end{array}$ \\
\hline $\begin{array}{l}\text { Male Engineer from Local } \\
\text { Industry and Husband of an } \\
\text { Engineer }\end{array}$ & 15 & $\begin{array}{l}\text { The Engineering Family or seeing from the Male } \\
\text { Perspective } \\
\text { - being married to a female engineer } \\
\text { - juggling family issues between two careers }\end{array}$ \\
\hline $\begin{array}{l}\text { Flexible Learning Services } \\
\text { CEDIR, Acting Manager }\end{array}$ & 5 & $\begin{array}{l}\text { Assessment/Assignment } \\
-\quad \text { presentation of the Diversity in Engineering project }\end{array}$ \\
\hline Lecturer & 5 & Conclusions \& Collection of Questionnaires \\
\hline
\end{tabular}


Schäfer, A.I. (2006) A new Approach to increasing diversity in engineering at the example of women in engineering,

European Journal of Engineering Education, Volume 31, Issue 6 December 2006 , pages 661 - 671

Table 2 Questions asked in the anonymous questionnaire collected at the end of the lecture.

Gender

\begin{tabular}{l|l}
1 & Gtatus (Student/Academic Staff/General Staff)
\end{tabular}

3 Engineering Discipline

4 One a scale of 0 (low) to 10 (high) awareness of diversity in engineering issues before attending this lecture. Any comments on the answer? (such as reasons for level of awareness?)

5 One a scale of 0 (low) to 10 (high) awareness of diversity in engineering issues after attending this

lecture. Any comments on the answer? (such as how this lecture made a difference or why it didn't?)

6 How could we improve the communication of diversity issues in engineering?

7 Any comments to share on the lecture or associated issues.
Figure 1 Percentage of female students in the Faculty of Engineering at UoW by engineering discipline. Average student numbers are over this 2000-2003 period civil 225; environmental 62; materials 61: mechanical 191: mechatronics 42; mining 50. Total student numbers are students enrolled over the entire 4 year degree program.

Figure $2 \mathrm{Awareness}$ of participants before and after diversity in engineering lecture

Figure 3 Number of participants for increase in awareness levels achieved 
Schäfer, A.I. (2006) A new Approach to increasing diversity in engineering at the example of women in engineering,

European Journal of Engineering Education, Volume 31, Issue 6 December 2006 , pages 661 - 671

FIGURE 1

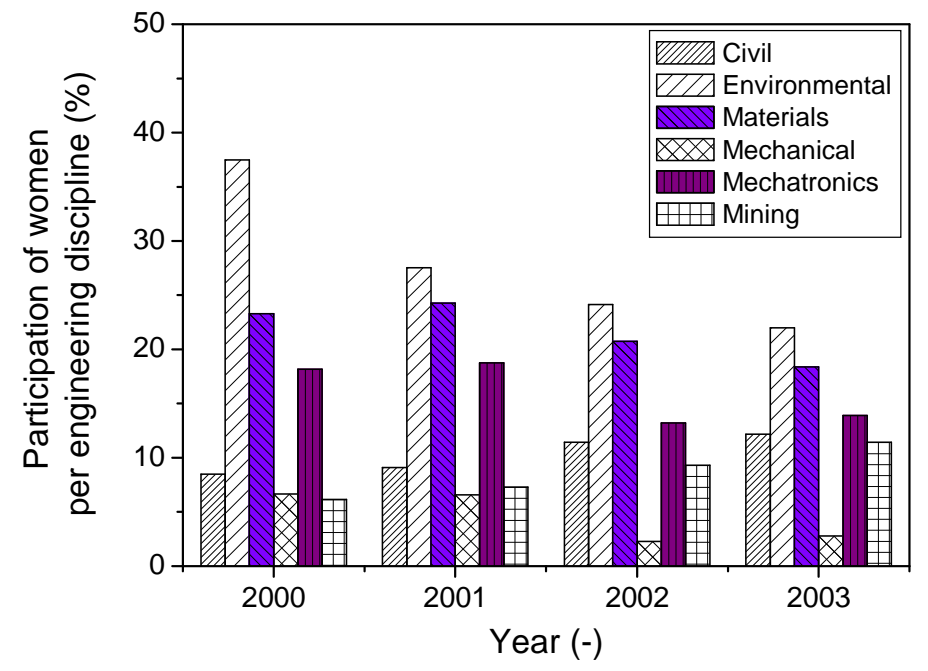

FIGURE 2

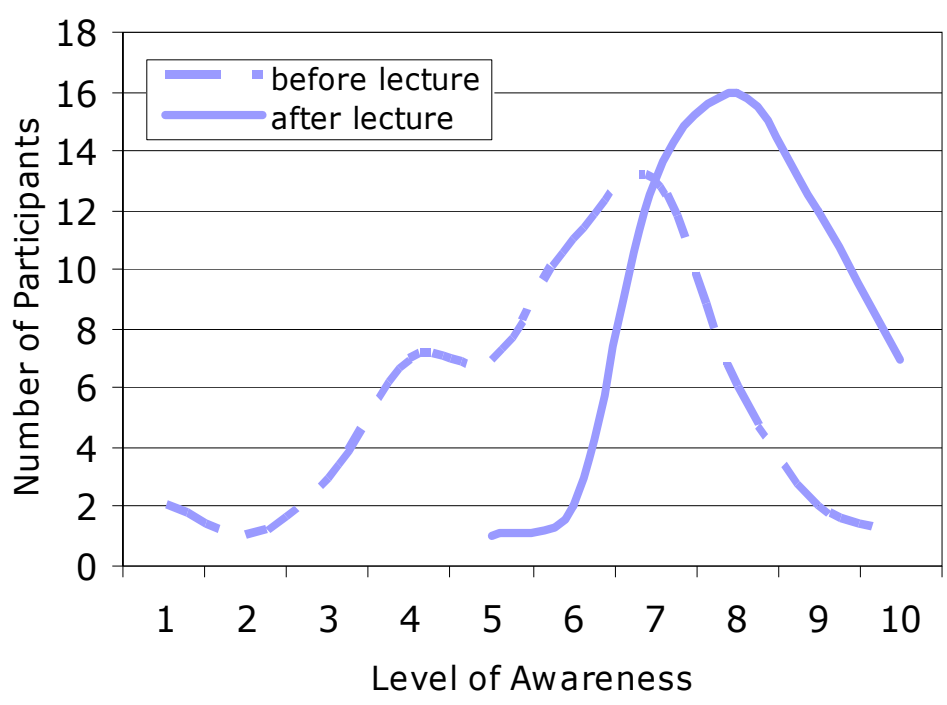


Schäfer, A.I. (2006) A new Approach to increasing diversity in engineering at the example of women in engineering,

European Journal of Engineering Education, Volume 31, Issue 6 December 2006 , pages 661 - 671

FIGURE 3

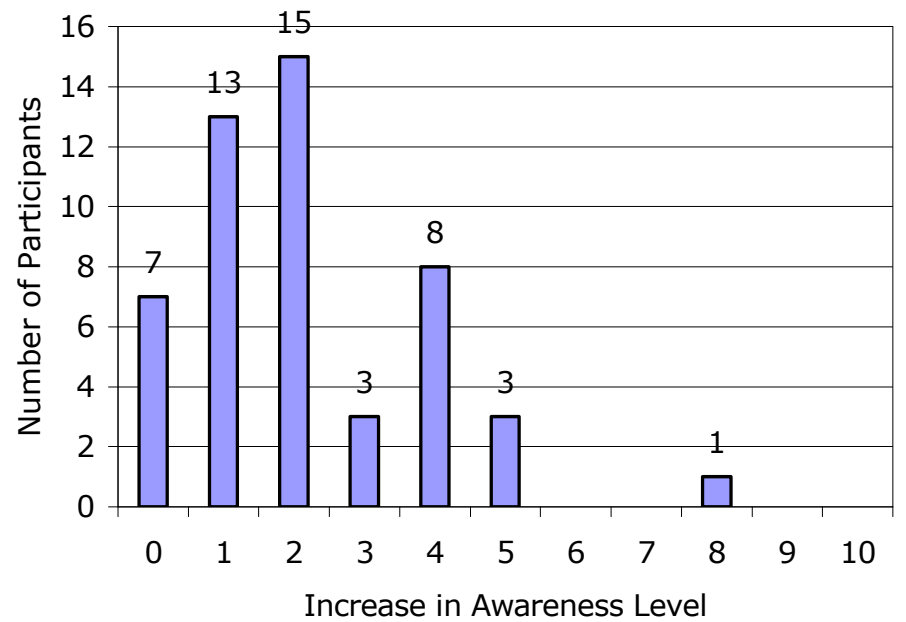

